\title{
BMJ Open Onset seasons and clinical outcomes in patients with Stanford type A acute aortic dissection: an observational retrospective study
}

\author{
Zhaoran Chen, ${ }^{1}$ Bi Huang, ${ }^{1}$ Yanmin Yang, ${ }^{1}$ Rutai Hui, ${ }^{1}$ Haisong Lu, ${ }^{2}$ \\ Zhenhua Zhao, ${ }^{2}$ Zhinan Lu, ${ }^{1}$ Shu Zhang, ${ }^{1}$ Xiaohan Fan ${ }^{1}$
}

To cite: Chen Z, Huang B, Yang $Y$, et al. Onset seasons and clinical outcomes in patients with Stanford type A acute aortic dissection: an observational retrospective study. BMJ Open 2017;7: e012940. doi:10.1136/ bmjopen-2016-012940

- Prepublication history and additional material is available. To view please visit the journal (http://dx.doi.org/ 10.1136/bmjopen-2016012940).

Received 7 June 2016 Revised 18 November 2016 Accepted 16 January 2017

CrossMark

\footnotetext{
${ }^{1}$ State Key Laboratory of Cardiovascular Disease, Department of Cardiology, Fuwai Hospital, National Center for Cardiovascular Diseases, Peking Union Medical College, Beijing, China ${ }^{2}$ State Key Laboratory of Cardiovascular Disease, Department of Cardiovascular Surgery, Fuwai Hospital, National Center for Cardiovascular Diseases, Peking Union Medical College, Beijing, China

Correspondence to Dr Xiaohan Fan; ehan4348ff@gmail.com, or Dr Yanmin Yang; yymwin@gmail.com
}

\section{ABSTRACT}

Objectives: To evaluate the association of onset season with clinical outcome in type A acute aortic dissection (AAD).

Design: A single-centre, observational retrospective study.

Setting: The study was conducted in Fuwai Hospital, the National Centre for Cardiovascular Disease, Beijing, China.

Participants: From 2008 to 2010, a set of consecutive patients with type A AAD, confirmed by CT scanning, were enrolled and divided into four groups according to onset season: winter (December, January and February), spring (March, April and May), summer (June, July and August) and autumn

(September, October and November). The primary end points were in-hospital death and all-cause mortality during follow-up.

Results: Of the 492 cases in this study, 129 occurred in winter $(26.2 \%), 147$ in spring $(29.9 \%)$, 92 in summer $(18.7 \%)$, and 124 in autumn $(25.2 \%)$. After a median follow-up of 20.4 months (IQR 9.738.9 ), the in-hospital mortality in cases occurring in autumn was higher than in the other three seasons $(23.4 \%$ vs $8.4 \%, p<0.01)$. Long-term mortality was comparable among the four seasonal groups $(p=0.63)$. After adjustment for age, gender and other risk factors, onset in autumn was still an independent factor associated with increased risk of in-hospital mortality (HR 2.05; $95 \% \mathrm{Cl} 1.15$ to 3.64 , $\mathrm{p}=0.02$ ) in addition to surgical treatment. Further analysis showed that the seasonal effect on inhospital mortality (autumn vs other seasons: $57.4 \%$ vs $27.3 \%, p<0.01$ ) was only significant in patients who did not receive surgical treatment. No seasonal effect on long-term clinical outcomes was found in this cohort.

Conclusions: Onset in autumn may be a factor that increases the risk of in-hospital death from type $A$ $A A D$, especially in patients who receive conservative treatment. Immediate surgery improves the shortterm and long-term outcomes regardless of onset season.

\section{Strengths and limitations of this study}

- This is the first study to suggest that patients with type A acute aortic dissection (AAD) with onset in the 'hot-to-cold' transitional season of autumn had the worst short-term outcome.

- This is a large-sample study performed in a single centre with nearly 500 patients with type A AAD with both short- and long-term clinical outcomes.

- The findings in this study might not necessarily be mirrored in other regions because of the different regional and seasonal characteristics and the single-centre setting.

- The potential influence of meteorological factors such as temperature, humidity and air pressure could not be assessed because the relevant data were not available in this study.

\section{INTRODUCTION}

Acute aortic dissection (AAD) remains the most common aortic catastrophe, with management and prognosis determined by the location of the affected aortic segment. Stanford type A AAD, which involves the ascending aorta, is most severe and should be treated with urgent surgical intervention. ${ }^{1}$ Thus, identification of risk factors affecting prognosis is of great value for risk stratification. Previous studies have shown that cardiovascular conditions such as coronary heart disease, ${ }^{2-6}$ stroke, ${ }^{7} 8$ supraventricular tachycardia $^{9}$ and heart failure ${ }^{10}$ are associated with seasonal variations. The incidences of these events show distinct seasonal patterns, with peak admissions during the winter. Also, seasonal frequency variations for aortic dissection (AD) have been recorded and show that the incidence peaks in winter and is lowest in summer. ${ }^{1-17}$ However, a few studies have investigated the prognostic value of 
onset season in patients with $\mathrm{AAD}$, and they found that seasonal variation in the occurrence of $\mathrm{AAD}$ did not influence in-hospital outcomes. ${ }^{16}{ }^{18}$ Moreover, there is a lack of data on the association of onset season with longterm outcomes in patients with type A AAD. Therefore, we hypothesised that there would be a seasonal effect on in-hospital or long-term mortality in patients with type A AAD. This single-centre study enrolled consecutive patients at Fuwai Hospital to analyse the relationship between onset season and clinical outcome of type A AAD.

\section{METHODS}

\section{Patients}

From October 2008 to December 2010, consecutive patients with suspected type A AAD who were admitted to the emergency centre of Fuwai Hospital were enrolled. Although the population came from all over the country (figure 1), patients included in this study primarily came from Beijing and nearby areas. The diagnosis of type A AAD was confirmed by multidetector CT scanning. Patients were excluded if the exact date of onset of the illness was unknown or if they had a clear aetiology such as Marfan's syndrome, Loeys-Dietz syndrome, iatrogenic $\mathrm{AD}$ secondary to cardiac surgery, thoracic endovascular aortic repair, or a history of operation for $\mathrm{AD}$. All patients with chronic dissections or previous operation were also excluded. In-hospital survival analysis was performed on all patients included in the study, but long-term survival analysis was only performed on discharged patients. This study was approved by the ethics committee of Fuwai Hospital, and written informed consent was obtained from each patient. The study protocol conformed with the ethical guidelines of the 1975 Declaration of Helsinki as reflected in a priori approval by the institution's human research committee.

\section{Data collection}

Baseline characteristics data were recorded, including sex, age, duration of pain, and medical history including hypertension, diabetes mellitus, coronary artery disease, smoking status and drinking status. Other recorded clinical characteristics included baseline vital signs at admission (systolic/diastolic blood pressure and heart rate), imaging examinations and hospital management (medical therapy or surgical intervention). The rationale and strategy of the surgical techniques were determined by experienced surgeons in the Department of Cardiovascular Surgery in our hospital. In-hospital outcome data were gathered from medical records. After discharge, follow-up was performed via outpatient clinic visits or by telephone every 3 months.

\section{Season of symptom onset and clinical outcomes}

Information on the time of symptom onset was obtained from the history of the present illness in the patient's medical record. For the purpose of seasonal analysis, patients were divided according to their symptom onset into four groups by season: winter (December, January and February), spring (March, April and May), summer (June, July and August) and autumn (September, October and November). ${ }^{19}$ The study end points were in-hospital death and long-term all-cause mortality.

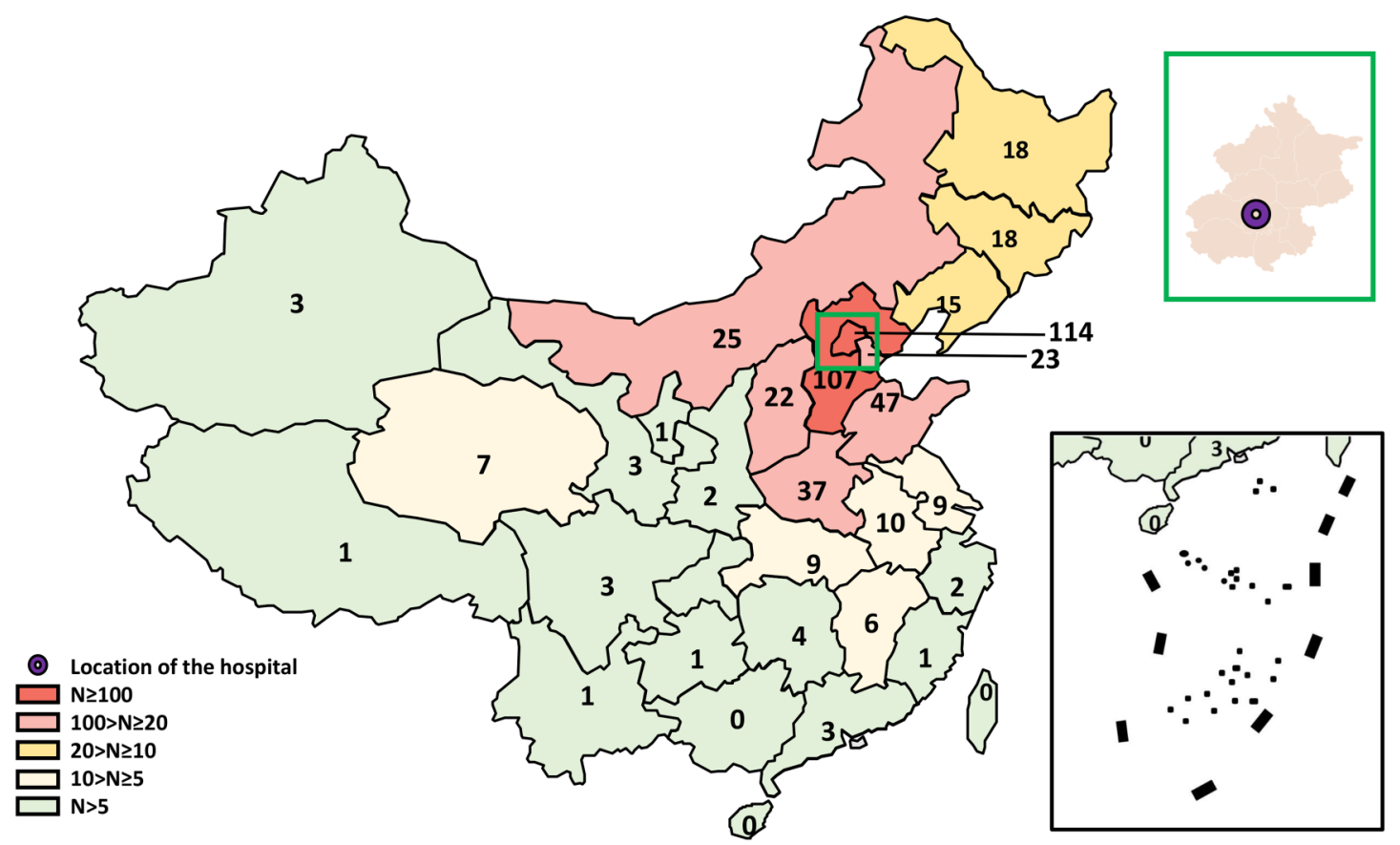

Figure 1 Geographical distribution of the patients enrolled in this study. Numbers represent patient count in the corresponding region. 


\section{Statistical analysis}

All statistical analyses were performed using SPSS V.19.0. Continuous variables are presented as mean $\pm \mathrm{SD}$ or median (IQR) according to whether or not they follow Gaussian distribution. Baseline characteristics were compared among the groups using analysis of variance or $\chi^{2}$ tests. Long-term survival analysis was only performed in discharged patients. In-hospital and long-term mortality among the seasonal groups were compared using $\chi^{2}$ tests. Kaplan-Meier survival curves for the groups stratified by onset season were constructed and compared using the log-rank test. A Cox proportional hazards regression model was used to assess the role of onset season as a factor affecting AAD survival. A $p$ value of $<0.05$ was considered significant.

\section{RESULTS}

Clinical features of cases of type A AAD occurring in each of the four seasons

After exclusion of cases of type A AAD with incomplete onset time data, a total of 492 were studied, of which 129 occurred in winter (26.2\%), 147 in spring (29.9\%), 92 in summer $(18.7 \%)$, and 124 in autumn (25.2\%). The average age of all patients was 48.4 years; 398 of the 492 patients $(80.9 \%)$ were male. The clinical characteristics of patients in the four groups are summarised in table 1 .

In general, no significant differences were found in most baseline characteristics among the four seasons. Regarding in-hospital management, treatment with calcium channel blockers and surgical intervention seemed to be significantly less common in patients with type A AAD that occurred in autumn than in patients with type A AAD that occurred in the other seasons (all $\mathrm{p}<0.05)$.

\section{Seasonal variation in in-hospital and long-term mortality in type A AAD}

During a mean follow-up of 20.4 months (IQR 9.7$38.9)$, total mortality was $17.3 \%(85 / 492)$ with in-hospital mortality of $12.2 \%(60 / 492)$ and long-term mortality of $5.8 \%(25 / 432)$. The actuarial survival rate at 1 year was $85.8 \%$ (422/492). In-hospital mortality in patients with type A AAD that occurred in autumn (23.4\%) was the highest, and that in patients with type A AAD that occurred in spring $(6.1 \%)$ was the lowest $(p<0.01)$. After exclusion of patients who died in hospital, long-term mortality was comparable among the four seasonal groups $(\mathrm{p}=0.63$, detailed in online supplementary table $\mathrm{S} 1$ ). When winter, spring and summer were collectively classified as the non-autumn group, in-hospital mortality was still significantly higher in the autumn group than in the non-autumn group (23.4\% vs $8.4 \%, \mathrm{p}<0.01)$, but long-term mortality did not differ significantly between the autumn and the non-autumn group $(4.2 \%$ vs $6.2 \%, \mathrm{p}=0.46)$.
Kaplan-Meier analysis showed that the cumulative in-hospital survival rate was significantly lower in patients with type A AAD occurring in autumn than in patients with type $\mathrm{A} A \mathrm{AD}$ occurring in the other three seasons $\left(\log\right.$ rank $\left.\chi^{2}=24.5, \mathrm{p}<0.01\right)$. As shown in figure $2 \mathrm{~A}$, the survival curves clearly began to separate by the first 2-5 days after admission to the emergency department. Figure 2B shows that the cumulative long-term survival rates were similar among the four seasonal groups in discharged patients $\left(\log \operatorname{rank} \chi^{2}=0.03, \mathrm{p}=0.83\right)$.

\section{Seasonal effect on in-hospital death of patients with type A AAD}

Table 2 shows the results of Cox regression analysis for predictors of in-hospital death from type A AAD.

Univariate Cox analysis revealed that onset in autumn was associated with a 3.01-fold increased risk of inhospital mortality (HR=3.01; 95\% CI 1.82 to $5.00, \mathrm{p}<0.01)$ compared with the non-autumn seasons. The other factors associated with in-hospital mortality included admission white blood cell (WBC) count $(\mathrm{HR}=1.21 ; 95 \%$ CI 1.15 to $1.26, \mathrm{p}<0.01)$, platelet count $(\mathrm{HR}=0.99 ; 95 \%$ CI 0.98 to $0.99, \mathrm{p}<0.01)$, d-dimer levels $(\mathrm{HR}=1.01 ; 95 \%$ CI 1.01 to $1.13, \mathrm{p}<0.01)$, serum creatinine levels $(\mathrm{HR}=1.01$; $95 \%$ CI 1.00 to $1.01, \mathrm{p}<0.01)$ and surgical intervention (HR $=0.01 ; 95 \%$ CI 0.00 to $0.05, \mathrm{p}<0.01)$. After adjustment by multivariate Cox regression for age, sex and other risk factors, onset in autumn was still an independent risk factor associated with in-hospital mortality from type A AAD (HR=2.05; 95\% CI 1.15 to 3.64, $\mathrm{p}=0.02)$. In-hospital death was still associated with admission WBC count ( $\mathrm{HR}=1.15 ; 95 \%$ CI 1.09 to $1.21, \mathrm{p}<0.01)$, platelet count ( $\mathrm{HR}=0.99 ; 95 \%$ CI 0.99 to $0.99, \mathrm{p}=0.01)$ and surgical intervention (HR $=0.01 ; 95 \%$ CI 0.00 to $0.06, \mathrm{p}<0.01)$ after multivariate Cox regression analysis.

\section{Seasonal effect on long-term mortality from type A AAD}

In discharged patients, univariate Cox analysis did not reveal any association between onset season (autumn or non-autumn) and long-term mortality (table 3). Multivariate Cox analysis confirmed no seasonal effect on long-term death from type A AAD. Surgical treatment was the main factor (HR=0.19; 95\% CI 0.08 to $0.45, \mathrm{p}<0.01)$ associated with long-term survival.

\section{Surgical treatment and seasonal effect on clinical outcomes of type A AAD}

Because of the significant impact of surgical treatment on both in-hospital and long-term death from type A $\mathrm{AAD}$, patients were subdivided into a surgical intervention group $(\mathrm{N}=329)$ and a medical treatment group $(\mathrm{N}=163)$. As shown in figure 3 , the rates of in-hospital death and long-term mortality were comparable between autumn and non-autumn onset for those who received surgical treatment (rate of in-hospital death, $0.0 \%$ vs $0.4 \%, \mathrm{p}=1.00$; rate of long-term mortality, $1.4 \%$ vs $4.3 \%$, $\mathrm{p}=0.43$ ). However, for those who received conservative treatment, in-hospital mortality was significantly higher 
Table 1 Baseline characteristics of patients with type A AAD onset in different seasons

\begin{tabular}{|c|c|c|c|c|c|}
\hline Characteristic & Winter ( $N=129)$ & Spring ( $N=147)$ & Summer $(\mathrm{N}=92)$ & Autumn (N=124) & p Value \\
\hline Age, years & $48.7 \pm 11.8$ & $47.7 \pm 11.0$ & $48.6 \pm 13.0$ & $48.1 \pm 12.2$ & 0.90 \\
\hline Male & $103(78.9)$ & $123(83.7)$ & $64(69.6)$ & 108(87.2) & 0.01 \\
\hline Hypertension & $97(75.2)$ & $96(65.3)$ & 68 (73.9) & $92(74.2)$ & 0.23 \\
\hline Diabetes mellitus & $0(0.0)$ & $5(3.4)$ & $9(9.8)$ & $2(1.6)$ & $<0.01$ \\
\hline Coronary artery disease & $6(4.7)$ & $6(4.1)$ & $8(8.7)$ & $3(2.4)$ & 0.21 \\
\hline Smoker & $42(37.8)$ & $61(41.5)$ & $33(35.9)$ & $44(35.5)$ & 0.79 \\
\hline Alcohol consumption & $27(20.9)$ & $36(24.5)$ & $13(14.1)$ & $23(18.5)$ & 0.25 \\
\hline Duration of pain, hours & $10.0(4.0-24.0)$ & $12.0(5.0-24.0)$ & $20.0(5.0-24.0)$ & $19(5.1-24.0)$ & 0.49 \\
\hline $\mathrm{SBP}, \mathrm{mm} \mathrm{Hg}$ & $131.8 \pm 22.1$ & $136.4 \pm 27.4$ & $140.6 \pm 26.0$ & $138.2 \pm 25.9$ & 0.09 \\
\hline $\mathrm{DBP}, \mathrm{mm} \mathrm{Hg}$ & $72.6 \pm 19.7$ & $76.2 \pm 18.5$ & $79.1 \pm 22.3$ & $78.5 \pm 18.5$ & 0.06 \\
\hline Heart rate, beats/min & $84.7 \pm 16.3$ & $85.3 \pm 16.5$ & $81.4 \pm 14.2$ & $83.0 \pm 15.0$ & 0.24 \\
\hline WBC count, $\times 10^{9}$ cells $/ \mathrm{L}$ & $9.7(7.1-13.4)$ & $9.9(7.6-12.5)$ & $9.4(6.5-13.5)$ & $10.2(7.9-14.1)$ & 0.48 \\
\hline Platelet count, $\times 10^{9}$ cells $/ \mathrm{L}$ & $177(144.0-236.5)$ & $175(132.0-221.0)$ & $176(140.0-233.0)$ & $200(139.0-267.8)$ & 0.16 \\
\hline C-reactive protein, mg/L & $8.0(4.5-55.9)$ & $7.9(3.91-46.4)$ & $5.8(3.7-33.0)$ & $5.7(3.7-46.9)$ & 0.06 \\
\hline $\mathrm{d}$-Dimer, $\mathrm{mg} / \mathrm{L}$ & $3.3(1.4-5.2)$ & $3.1(1.3-5.7)$ & $3.8(1.4-7.9)$ & $4.5(2.1-9.2)$ & 0.10 \\
\hline Serum creatinine, $\mu \mathrm{mol} / \mathrm{L}$ & $90.9(73.2-117.0)$ & $89.0(74.0-115.0)$ & $86(75.0-111.0)$ & $92.5(74.9-127.3)$ & 0.57 \\
\hline Ascending aorta diameter, $\mathrm{mm}$ & $44.7 \pm 10.0$ & $47.0 \pm 10.9$ & $44.6 \pm 13.4$ & $45.7 \pm 11.5$ & 0.30 \\
\hline \multicolumn{6}{|l|}{ Treatment } \\
\hline$\beta$-Blocker & $99(76.7)$ & $119(81.0)$ & $76(82.6)$ & $96(77.4)$ & 0.65 \\
\hline CCB & $84(65.1)$ & $114(77.6)$ & $63(68.5)$ & $59(47.6)$ & $<0.01$ \\
\hline ACEI & $67(46.7)$ & $72(48.2)$ & $40(43.5)$ & $51(41.1)$ & 0.30 \\
\hline ARB & $19(14.7)$ & $16(10.9)$ & $11(12.0)$ & 14 (11.3) & 0.78 \\
\hline Surgical intervention & $80(62.0)$ & $108(73.5)$ & $70(76.1)$ & $71(57.3)$ & 0.01 \\
\hline
\end{tabular}

Values are mean $\pm S D, n(\%)$ or median (IQR).

$\mathrm{AAD}$, acute aortic dissection; ACEI, ACE inhibitor; ARB, angiotensin receptor blocker; CCB, calcium channel blocker; DBP, diastolic blood pressure; SBP, systolic blood pressure; WBC, white blood cell. 

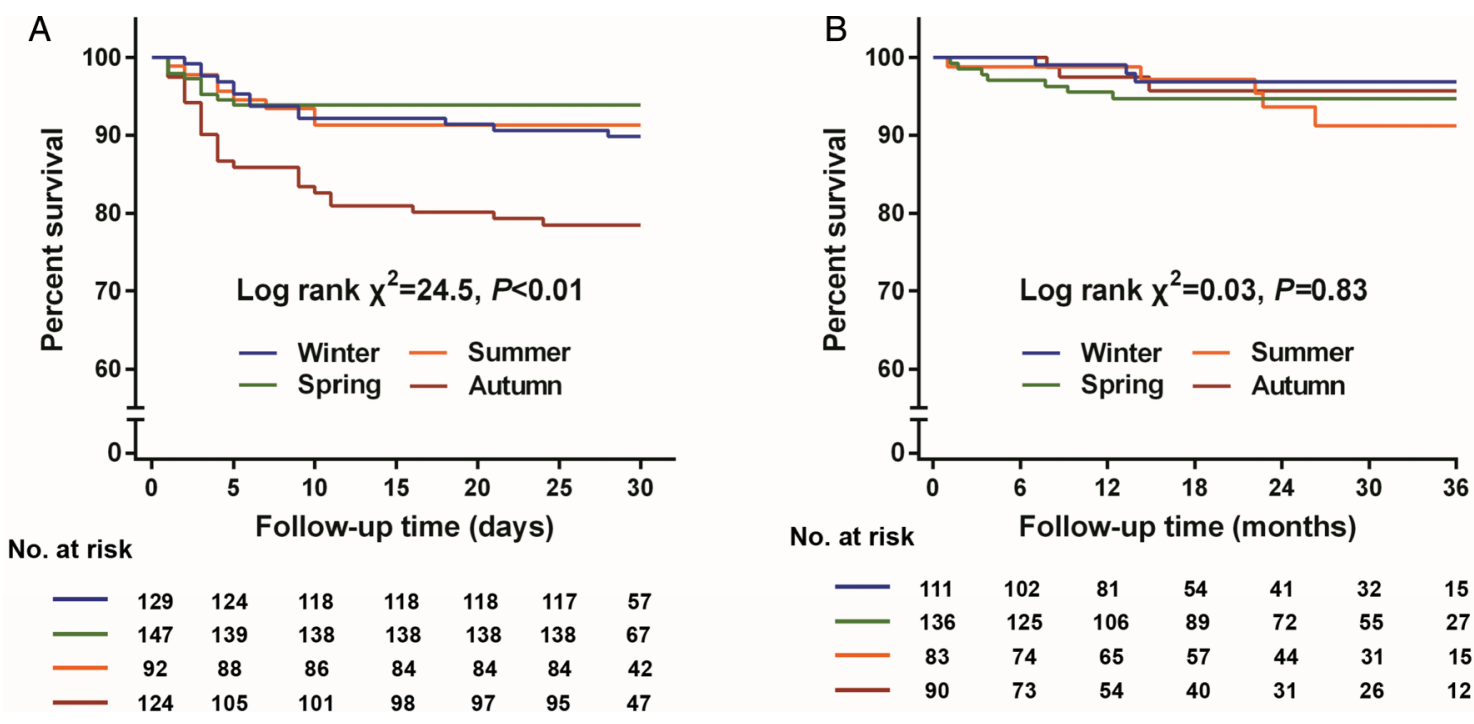

Figure 2 Survival curves according to onset season (winter, spring, summer and autumn). (A) Kaplan-Meier curves for in-hospital survival according to onset season (in all patients); (B) Kaplan-Meier curves for long-term survival according to onset season (in discharged patients).

Table 2 Predictors of in-hospital mortality by univariate and multivariate Cox analysis

\begin{tabular}{|c|c|c|c|c|c|c|}
\hline \multirow[b]{2}{*}{ Variable } & \multicolumn{3}{|c|}{ Univariate } & \multicolumn{3}{|c|}{ Multivariate } \\
\hline & HR & $95 \% \mathrm{Cl}$ & p Value & HR & $95 \% \mathrm{Cl}$ & p Value \\
\hline Age, per year (continuous) & 0.99 & 0.97 to 1.01 & 0.36 & 0.98 & 0.96 to 1.02 & 0.11 \\
\hline Gender, male vs female & 1.34 & 0.66 to 2.72 & 0.42 & 1.15 & 0.55 to 2.39 & 0.72 \\
\hline Autumn, vs other seasons & 3.01 & 1.82 to 5.00 & $<0.01$ & 2.05 & 1.15 to 3.64 & 0.02 \\
\hline Autumn vs winter & 2.35 & 1.24 to 4.44 & 0.01 & - & - & - \\
\hline Autumn vs spring & 4.10 & 1.94 to 8.67 & $<0.01$ & - & - & - \\
\hline Autumn vs summer & 2.92 & 1.34 to 6.40 & $<0.01$ & - & - & - \\
\hline Pericardial effusion & 1.34 & 0.76 to 2.35 & 0.31 & - & - & - \\
\hline WBC count, per $1 \times 10^{9}$ cells/L (continuous) & 1.21 & 1.15 to 1.26 & $<0.01$ & 1.15 & 1.09 to 1.21 & $<0.01$ \\
\hline Platelet count, per $1 \times 10^{9}$ cells/L (continuous) & 0.99 & 0.98 to 0.99 & $<0.01$ & 0.99 & 0.99 to 0.99 & 0.01 \\
\hline $\mathrm{d}$-Dimer, per $1 \mathrm{mg} / \mathrm{L}$ (continuous) & 1.01 & 1.01 to 1.13 & $<0.01$ & 1.02 & 0.97 to 1.07 & 0.42 \\
\hline C-reactive protein, per $1 \mathrm{mg} / \mathrm{L}$ (continuous) & 1.00 & 1.00 to 1.01 & 0.06 & - & - & - \\
\hline Serum creatinine, per $1 \mu \mathrm{mol} / \mathrm{L}$ (continuous & 1.01 & 1.00 to 1.01 & $<0.01$ & 1.00 & 0.99 to 1.00 & 0.86 \\
\hline Ascending aorta diameter, per $1 \mathrm{~mm}$ (continuous) & 1.01 & 0.98 to 1.03 & 0.54 & - & - & - \\
\hline Surgical intervention & 0.01 & 0.00 to 0.05 & $<0.01$ & 0.01 & 0.00 to 0.06 & $<0.01$ \\
\hline
\end{tabular}

in patients whose onset was autumn than in those whose onset was non-autumn $(57.4 \%$ vs $27.3 \%, \mathrm{p}<0.01)$, while no differences were observed in long-term mortality between autumn and non-autumn onset in patients who were discharged $(12.5 \%$ vs $12.5 \%, \mathrm{p}=1.00)$.

\section{DISCUSSION}

This retrospective clinical study analysed the association of onset season for type A AAD with short- and longterm clinical outcomes. Our results show that patients with onset in autumn had higher in-hospital mortality than those with onset in other seasons. Long-term mortality did not differ among patients with onset in the four different seasons. After adjustment by multivariate Cox analysis, the seasonal effect of onset in autumn on in-hospital death in patients with acute type A AAD was still significant. Our study also confirmed that surgical intervention was an independent protective factor that could significantly reduce both in-hospital and longterm death.

Previous studies suggested a possible seasonal effect on the onset of AAD by reporting a high incidence of $\mathrm{AAD}$ in winter and a low incidence of AAD in summer. Although Mehta et $a l^{11}$ reported a seasonal pattern characterised by a winter onset peak only for type B but not for type A AAD by analysing International Registry of Aortic Dissection (IRAD) data, their further analysis of patients with $\mathrm{AD}$ (without classification) showed that the winter categorisation was independent of climatic zone. $^{15}$ A meta-analysis of 60567 patients with acute aortic rupture and dissection (AARD) also found a 
Table 3 Predictors of long-term mortality by univariate and multivariate Cox analysis in patients who were discharged

\begin{tabular}{|c|c|c|c|c|c|c|}
\hline \multirow[b]{2}{*}{ Variable } & \multicolumn{3}{|c|}{ Univariate } & \multicolumn{3}{|c|}{ Multivariate } \\
\hline & HR & $95 \% \mathrm{CI}$ & p Value & HR & $95 \% \mathrm{Cl}$ & p Value \\
\hline Age, per year (continuous) & 1.01 & 0.97 to 1.04 & 0.77 & 0.99 & 0.97 to 1.03 & 0.97 \\
\hline Gender, male vs female & 0.67 & 0.27 to 1.69 & 0.40 & 0.74 & 0.29 to 1.91 & 0.54 \\
\hline Autumn, vs other seasons & 0.75 & 0.26 to 2.21 & 0.61 & 0.66 & 0.22 to 1.97 & 0.46 \\
\hline Autumn vs winter & 0.96 & 0.26 to 3.62 & 0.96 & - & - & - \\
\hline Autumn vs spring & 0.59 & 0.18 to 1.89 & 0.37 & - & - & - \\
\hline Autumn vs summer & 0.83 & 0.22 to 3.10 & 0.78 & - & - & - \\
\hline Pericardial effusion & 1.90 & 0.83 to 4.36 & 0.13 & - & - & - \\
\hline WBC count, per $1 \times 10^{9}$ cells $/ L$ (continuous) & 0.94 & 0.84 to 1.06 & 0.32 & 0.94 & 0.83 to 1.06 & 0.28 \\
\hline Platelet count, per $1 \times 10^{9}$ cells/L (continuous) & 1.04 & 0.99 to 1.01 & 0.06 & 1.00 & 0.99 to 1.01 & 0.11 \\
\hline d-Dimer, per 1 mg/L (continuous) & 1.03 & 0.96 to 1.11 & 0.37 & - & - & - \\
\hline C-reactive protein, per $1 \mathrm{mg} / \mathrm{L}$ (continuous) & 1.00 & 0.99 to 1.01 & 0.88 & - & - & - \\
\hline Serum creatinine, per $1 \mu \mathrm{mol} / \mathrm{L}$ (continuous) & 1.00 & 0.98 to 1.01 & 0.66 & - & - & - \\
\hline Ascending aorta diameter, per $1 \mathrm{~mm}$ (continuous) & 0.99 & 0.96 to 1.03 & 0.59 & - & - & - \\
\hline Surgical intervention & 0.20 & 0.09 to 0.44 & $<0.01$ & 0.19 & 0.08 to 0.45 & $<0.01$ \\
\hline
\end{tabular}

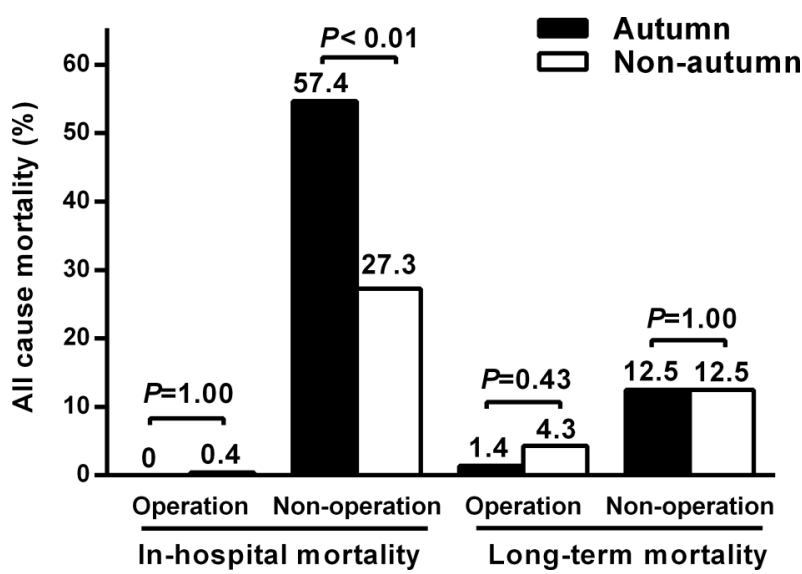

Figure 3 Comparison of all-cause mortality stratified by whether the patient had an operation and whether onset was in autumn.

winter increase in AARD incidence. ${ }^{13}$ In addition, a study that included 89365 cases of AAD in the USA demonstrated that the incidence of AAD was highest in January and lowest in July. ${ }^{16}$ An Italian study that included 4615 patients with AAD also showed the highest incidence in January and the lowest incidence in August. ${ }^{20}$ The reason for this seasonal pattern is not fully clear. The cold weather in winter can lead to increased sympathetic activity (vasoconstriction, vascular spasm and increased blood pressure). The haemorheological changes in winter (increased blood viscosity and altered coagulation and fibrinolytic systems) may also make the aorta vulnerable to high blood pressure. ${ }^{17}$

It has been noticed that non-accidental mortality increased sharply in the transitional season in the general population. Kalkstein ${ }^{21}$ found evidence of a two-step increase in mortality during transition from hot to cold seasons in Minneapolis and Detroit in the USA.
Mortality begins to increase steadily in early September, flattens out from mid-October through mid-November, and then increases rapidly until the first week of January. A similar finding for mortality distribution in transitional seasons in Russia was reported, ${ }^{22}$ and the increase in mortality was greater going from hot to cold (autumn) than from cold to hot (spring). In the north of China, which has distinct seasonal patterns characterised by transition from very hot wet summers to extremely cold dry winters during a short period in the first month of autumn, it is observed that large day-to-day temperature changes and diurnal temperature variation can increase the risk of cardiac mortality. ${ }^{23}{ }^{24} \mathrm{~A}$ rapid decrease in temperature is associated with a reduction in lung function ${ }^{25}$ and elevated resting metabolism during acute cold stress. ${ }^{26}{ }^{27}$ In the area in which this study was carried out, temperatures in autumn change dramatically, which may exacerbate the imbalance of homoeostasis in patients with severe disease such as hypertension. However, with the increasing industrialisation and urbanisation of northern China, most people are living in relatively stable warm conditions in the winter. Moreover, the universal use of air conditioning has made a relatively comfortable cool environment for people in summer. However, the transitional season effect on the body has been mainly overlooked. Previous studies investigated the prognostic value of the onset season in patients with $\mathrm{AAD}$, but they did not find any effect of seasonality on the outcome and in-hospital clinical events. ${ }^{16} 18$ This may be due to the differences in demographic and geographic characteristics between China and the West. Other studies have shown that excess morbidity and mortality in winter are associated with stroke and myocardial infarction. ${ }^{28}{ }^{29}$ Cardiovascular death has been found to occur less frequently in the summer months. ${ }^{30}$ The seasonal effect on cardiovascular death indicates that the season of onset of cardiovascular 
disease might be an overlooked factor associated with clinical outcomes.

The pathological basis for most $\mathrm{AD}$ is a mediolytic (dissolution of components of the medial layer) or dysplastic (abnormal proliferation of smooth muscle cells leading to a thickened arterial wall) artery, resulting in relative vulnerability of the blood vessels. ${ }^{31}$ Laplace's law has traditionally been used to describe the arterial deformation and rupture; it states that the circumferential wall tension is a linear function of the aortic radius and the pressure gradient across the aortic wall, which is dependent on both the intraluminal blood pressure and the extraluminal tissue pressure. ${ }^{17}$ The weakened aortic wall tends to rupture when the pressure gradient changes dramatically and the mechanical stress acting on the wall exceeds the strength of the wall tissue. ${ }^{32}$

Seasonality is mainly influenced by climate changes including temperature, atmospheric pressure (AP), humidity and other meteorological variables. There is much evidence that seasonal meteorological variables influence blood pressure in both hypertensive and normotensive individuals, ${ }^{33-35}$ and decreased outdoor temperature is in some way accompanied by increased intravascular systolic pressure. ${ }^{36}$ Changes in AP may increase transmural arterial stress by transiently lowering tissue pressure with respect to blood pressure, creating a net expansive force. ${ }^{37}$ The alteration in AP could also affect the partial pressure of oxygen and carbon dioxide in the circulation ${ }^{38}$ and thus activate chemoreceptors and baroreceptors leading to elevated sympathetic stimulation. Some studies have confirmed that the fluctuation in AP might increase the risk of rupture in abdominal aortic aneurysm. ${ }^{12}{ }^{37}$ In autumn, it becomes cold and wet due to frequent rain precipitation, with aggregate fluctuations in $\mathrm{AP}^{39}$ The decrease in temperature and change in AP may cause sympathetic activity to increase, resulting in vasoconstriction, increased blood pressure and vasospasm, and increasing or sharp fluctuations in systolic blood pressure may lead to increased risk of dissection rupture. These might be the reasons for the poor outcomes of patients with onset in autumn. In addition to the autumn months (September, October and November), this study found a high in-hospital mortality associated with onset in February, which also has fluctuating weather patterns. There is a traditional Chinese saying 'warming spring and freezing fall', which means people should keep warm in spring and wear less clothing in autumn to preadapt and minimise the effects of environmental change on the body. Alternating seasons and sudden changes in both temperature and AP can cause patients' conditions to deteriorate during treatment, but more studies are needed to further clarify the relationships between $\mathrm{AD}$, seasonal changes and treatment (especially drug therapy). It is widely accepted that surgery can significantly improve the outcome of type $\mathrm{A} \mathrm{AAD}$, and the in-hospital death rate of patients who have received surgery is lower than that of patients who have received conservative therapy. Our analysis also indicated that the short-term prognosis of patients undergoing surgery was not affected by onset season. In addition, this study suggests that conservative treatment could increase the risk of in-hospital death for patients with onset in autumn, and more aggressive treatment should be administered.

There are some limitations in this study. First, our data did not include temperature, humidity, AP and other specific climate data, which may have provided a more thorough explanation for the seasonal effect. The second limitation is our single-centre study design: our findings might not necessarily be mirrored in other countries with more temperate climates.

\section{CONCLUSION}

Seasonal patterns may exist in prognosis of type A AAD. Onset in autumn may be a factor that increases the risk of in-hospital death from type A AAD, especially in patients who receive conservative treatment. Urgent surgery improves the short-term and long-term outcomes regardless of onset season.

Acknowledgements We are very grateful to the patients and doctors who took part in the study and for the help and cooperation of clinic staff.

Contributors ZC, XF and YY participated in the study design. ZC and BH performed the data analysis. $\mathrm{HL}, \mathrm{ZZ}, \mathrm{ZL}, \mathrm{SZ}$ and RH helped with patient data collection and follow-up. The first draft of the manuscript was written by ZC and XF. All authors interpreted the results, revised the report, commented on the manuscript and approved the final version.

Funding This work was supported by two grants (grant numbers 81570430 and 81441017 ) from the National Natural Science Foundation of China to XF.

Competing interests None declared.

Patient consent Obtained.

Ethics approval Study protocols were approved by the appropriate institutional review boards of Fuwai Hospital and complied with the Declaration of Helsinki.

Provenance and peer review Not commissioned; externally peer reviewed.

Data sharing statement No additional data are available.

Open Access This is an Open Access article distributed in accordance with the Creative Commons Attribution Non Commercial (CC BY-NC 4.0) license, which permits others to distribute, remix, adapt, build upon this work noncommercially, and license their derivative works on different terms, provided the original work is properly cited and the use is non-commercial. See: http:// creativecommons.org/licenses/by-nc/4.0/

\section{REFERENCES}

1. Coady MA, Rizzo JA, Goldstein LJ, et al. Natural history, pathogenesis, and etiology of thoracic aortic aneurysms and dissections. Cardiol Clin 1999;17:615-35; vii.

2. Kono T, Morita $\mathrm{H}$, Nishina $\mathrm{T}$, et al. Circadian variations of onset of acute myocardial infarction and efficacy of thrombolytic therapy. J Am Coll Cardiol 1996;27:774-8.

3. Tofler $\mathrm{GH}$, Muller JE, Stone $\mathrm{PH}$, et al. Modifiers of timing and possible triggers of acute myocardial infarction in the Thrombolysis in Myocardial Infarction Phase II (TIMI II) Study Group. J Am Coll Cardiol 1992;20:1049-55.

4. Marchant B, Ranjadayalan K, Stevenson R, et al. Circadian and seasonal factors in the pathogenesis of acute myocardial infarction: the influence of environmental temperature. $\mathrm{Br}$ Heart $\mathrm{J}$ 1993;69:385-7. 
5. Gnecchi-Ruscone T, Piccaluga E, Guzzetti S, et al. Morning and Monday: critical periods for the onset of acute myocardial infarction. The GISSI 2 Study experience. Eur Heart J 1994;15:882-7.

6. Willich $\mathrm{SN}$, Lowel $\mathrm{H}$, Lewis $\mathrm{M}$, et al. Weekly variation of acute myocardial infarction. Increased Monday risk in the working population. Circulation 1994;90:87-93.

7. Kelly-Hayes M, Wolf PA, Kase CS, et al. Temporal patterns of stroke onset. The Framingham Study. Stroke 1995;26:1343-7.

8. Manfredini R, Gallerani M, Portaluppi F, et al. Chronobiological patterns of onset of acute cerebrovascular diseases. Thromb Res 1997;88:451-63.

9. Manfredini R, Gallerani M, Portaluppi F, et al. Circadian variation in the occurrence of paroxysmal supraventricular tachycardia in clinically healthy subjects. Chronobiol Int 1995;12:55-61.

10. Stewart S, McIntyre K, Capewell S, et al. Heart failure in a cold climate. Seasonal variation in heart failure-related morbidity and mortality. J Am Coll Cardiol 2002;39:760-6.

11. Mehta RH, Manfredini R, Hassan F, et al. Chronobiological patterns of acute aortic dissection. Circulation 2002;106:1110-15.

12. Krdzalic A, Rifatbegovic Z, Krdzalic G, et al. Atmospheric pressure changes are associated with type $A$ acute aortic dissections and spontaneous abdominal aortic aneurysm rupture in Tuzla Canton. Med Arh 2014;68:156-8.

13. Vitale J, Manfredini R, Gallerani M, et al. Chronobiology of acute aortic rupture or dissection: a systematic review and a meta-analysis of the literature. Chronobiol Int 2015;32:385-94.

14. Manfredini R, Fabbian F, Manfredini F, et al. Chronobiology in aortic diseases-"is this really a random phenomenon?". Prog Cardiovasc Dis 2013;56:116-24.

15. Mehta RH, Manfredini R, Bossone E, et al. The winter peak in the occurrence of acute aortic dissection is independent of climate. Chronobiol Int 2005;22:723-9.

16. Kumar N, Pandey A, Venkatraman A, et al. Seasonality in acute aortic dissection related hospitalizations and mortality in the United States: a nationwide analysis from 2004-2011. Int J Cardiol 2015:179:321-2.

17. Kordzadeh A, Askari A, Panayiotopoulos Y. Atmospheric pressure and infra-renal abdominal aortic aneurysm rupture: a single observational study and a comprehensive review of literature. Int J Surg 2013;11:458-62.

18. Mehta RH, Manfredini R, Bossone E, et al. Does circadian and seasonal variation in occurrence of acute aortic dissection influence in-hospital outcomes? Chronobiol Int 2005;22:343-51.

19. Lim HS, Roychoudhuri R, Peto J, et al. Cancer survival is dependent on season of diagnosis and sunlight exposure. Int $J$ Cancer 2006;119:1530-6.

20. Manfredini R, Boari B, Manfredini F, et al. Seasonal variation in occurrence of aortic diseases: the database of hospital discharge data of the Emilia-Romagna region, Italy. J Thorac Cardiovasc Surg 2008; 135:442-4.

21. Kalkstein AJ. Regional similarities in seasonal mortality across the United States: an examination of 28 metropolitan statistical areas. PLOS ONE 2013;8:e63971.

22. de Freitas C, Grigorieva E. Role of acclimatization in weather-related human mortality during the transition seasons of autumn and spring in a thermally extreme mid-latitude continental climate. Int $J$ Environ Res Public Health 2015:12:14974-87.
23. Zheng S, Wang M, Li B, et al. Gender, age and season as modifiers of the effects of diurnal temperature range on emergency room admissions for cause-specific cardiovascular disease among the elderly in Beijing. Int J Environ Res Public Health 2016;13:447.

24. Onozuka D, Hagihara A. Associations of day-to-day temperature change and diurnal temperature range with out-of-hospital cardiac arrest. Eur J Prev Cardiol 2017;24:204-12.

25. Li S, Guo Y, Williams G, et al. The association between ambient temperature and children's lung function in Baotou, China. Int J Biometeorol 2015;59:791-8.

26. de Freitas CR, Grigorieva EA. The Acclimatization Thermal Strain Index (ATSI): a preliminary study of the methodology applied to climatic conditions of the Russian Far East. Int J Biometeorol 2009;53:307-15.

27. de Freitas CR, Grigorieva EA. The impact of acclimatization on thermophysiological strain for contrasting regional climates. Int J Biometeorol 2014;58:2129-37.

28. Myint PK, Vowler SL, Woodhouse PR, et al. Winter excess in hospital admissions, in-patient mortality and length of acute hospital stay in stroke: a hospital database study over six seasonal years in Norfolk, UK. Neuroepidemiology 2007;28:79-85.

29. Douglas AS, Russell D, Allan TM. Seasonal, regional and secular variations of cardiovascular and cerebrovascular mortality in New Zealand. Aust N Z J Med 1990;20:669-76.

30. Reavey M, Saner H, Paccaud F, et al. Exploring the periodicity of cardiovascular events in Switzerland: variation in deaths and hospitalizations across seasons, day of the week and hour of the day. Int J Cardiol 2013;168:2195-200.

31. Grond-Ginsbach C, Pjontek R, Aksay SS, et al. Spontaneous arteria dissection: phenotype and molecular pathogenesis. Cell Mol Life Sci 2010;67:1799-815.

32. Raghavan ML, Vorp DA, Federle MP, et al. Wall stress distribution on three-dimensionally reconstructed models of human abdominal aortic aneurysm. J Vasc Surg 2000;31:760-9.

33. Stergiou GS, Myrsilidi A, Kollias A, et al. Seasonal variation in meteorological parameters and office, ambulatory and home blood pressure: predicting factors and clinical implications. Hypertens Res 2015;38:869-75.

34. Lewington S, Li L, Sherliker P, et al. Seasonal variation in blood pressure and its relationship with outdoor temperature in 10 diverse regions of China: the China Kadoorie Biobank. J Hypertens 2012;30:1383-91.

35. Kimura $\mathrm{T}$, Senda $\mathrm{S}$, Masugata $\mathrm{H}$, et al. Seasonal blood pressure variation and its relationship to environmental temperature in healthy elderly Japanese studied by home measurements. Clin Exp Hypertens 2010;32:8-12.

36. Yang L, Li L, Lewington S, et al. Outdoor temperature, blood pressure, and cardiovascular disease mortality among 23000 individuals with diagnosed cardiovascular diseases from China. Eur Heart J 2015;36:1178-85.

37. Harkin DW, O'Donnell M, Butler J, et al. Periods of low atmospheric pressure are associated with high abdominal aortic aneurysm rupture rates in Northern Ireland. Ulster Med J 2005;74:113-21.

38. Burnett RW, Itano M. An interlaboratory study of blood-gas analysis: dependence of $\mathrm{pO} 2$ and $\mathrm{pCO} 2$ results on atmospheric pressure. Clin Chem 1989;35:1779-81.

39. Wei J, Guoyu R, Yan Q. Change of surface pressure in Northeast China during 1961-2008. Plateau Meteorol 2011;2011:1661-7. 
Correction: Onset seasons and clinical outcomes in

patients with Stanford type A acute aortic dissection: an observational retrospective study

Chen Z, Huang B, Yang Y, et al. Onset seasons and clinical outcomes in patients with Stanford type A acute aortic dissection: an observational retrospective study BMJ Open 2017;7:e012940. doi: 10.1136/bmjopen-2016-012940

This article was previously published with an incorrect affiliation.

Affiliation number 1 was previously stated as

State Key Laboratory of Cardiovascular Disease, Department of Cardiology, Fuwai Hospital, National Center for Cardiovascular Diseases, Peking Union Medical College, Beijing, China

This should instead read as follows:

State Key Laboratory of Cardiovascular Disease, Department of Cardiology, Fuwai Hospital, National Center for Cardiovascular Diseases, Chinese Academy of Medical Sciences and Peking Union Medical College, Beijing, China

Open access This is an open access article distributed in accordance with the Creative Commons Attribution Non Commercial (CC BY-NC 4.0) license, which permits others to distribute, remix, adapt, build upon this work non-commercially, and license their derivative works on different terms, provided the original work is properly cited, appropriate credit is given, any changes made indicated, and the use is non-commercial. See: http://creativecommons.org/licenses/by-nc/4.0/.

(c) Article author(s) (or their employer(s) unless otherwise stated in the text of the article) 2018. All rights reserved. No commercial use is permitted unless otherwise expressly granted.

BMJ Open 2018;8:e012940corr1. doi:10.1136/bmjopen-2016-012940corr1

A) Check for updates 